\title{
Raman spectroscopy for detection of imatinib in plasma: A proof of concept
}

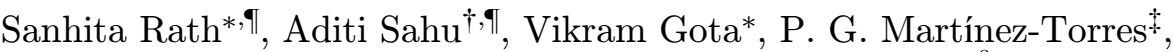 \\ J. L. Pichardo-Molinall and C. Murali Krishna ${ }^{\dagger, \S}$ \\ *Department of Clinical Pharmacology, ACTREC \\ Tata Memorial Center, Kharghar \\ Navi Mumbai 410210 India \\ ${ }^{\dagger}$ Chilakapati Lab, ACTREC, Tata Memorial Center \\ Kharghar, Navi Mumbai 410210 India \\ Instituto de Física y Matemáticas \\ Universidad Michoacana de San Nicolás de Hidalgo \\ Edificio C-3, Ciudad Universitaria \\ CP. 58040 Morelia, Michoacán, México \\ ${ }^{\|}$Centro de Investigaciones en Óptica $A C$ \\ C.P. 37 \#150, León Gto., Mexico \\ $\S_{\text {mchilakapati@actrec.gov.in }}$ \\ \$pittu1043@gmail.com
}

Received 4 August 2014

Accepted 6 November 2014

Published 22 December 2014

\begin{abstract}
Imatinib is the standard first line treatment for chronic myeloid leukemia (CML). Owing to doserelated toxicities of Imatinib such as neutropenia, there is scope for treatment optimization through therapeutic drug monitoring (TDM). Trough concentration of $1 \mu \mathrm{g} / \mathrm{mL}$ is considered the therapeutic threshhold. Existing methods for the detection of Imatinib in plasma are limited by long read out time and expensive instrumentation. Hence, Raman spectroscopy was explored as a rapid and objective tool for monitoring Imatinib concentration. Three approaches: conventional Raman spectroscopy (CRS), Drop coating deposition Raman (DCDR) spectroscopy and surface-enhanced Raman spectroscopy (SERS) were employed to detect the required trough concentration of $1 \mu \mathrm{g} /$ $\mathrm{mL}$ and above. Detection of therapeutically relevant concentrations $(1 \mu \mathrm{g} / \mathrm{mL})$ using SERS and suitable nanoparticle substrates has been demonstrated. Prospectively, rigorous validation using clinical samples is necessary to confirm the utility of this approach in routine clinical usage.
\end{abstract}

Keywords: Therapeutic drug monitoring; Raman spectroscopy; Imatinib; SERS; DCDR; chronic myeloid leukemia.

\footnotetext{
$\S_{\text {Corresponding author. }}$
}

IEqually contributed.

This is an Open Access article published by World Scientific Publishing Company. It is distributed under the terms of the Creative Commons Attribution 3.0 (CC-BY) License. Further distribution of this work is permitted, provided the original work is properly cited. 


\section{Introduction}

Tyrosine kinase inhibitors revolutionized the concept of well-tolerated cancer therapy with the introduction of Imatinib for the first line treatment of chronic phase chronic myeloid leukemia (CML). Imatinib inhibits ABL and the BCR-ABL fusion protein, c-KIT, and the platelet-derived growth factor receptor (PDGF-R). ${ }^{1}$ It is also used for the treatment of Philadelphia positive acute lymphoblastic leukemia (ALL), gastrointestinal stromal tumors (GIST) and some cases of dermatofibrosarcoma protuberans. The standard dose used in adults is $400 \mathrm{mg}$ once daily, whereas children with Philadelphia chromosome-positive leukemia receive a standard daily dose of $340 \mathrm{mg} / \mathrm{m}^{2} .^{2}$ Trough Imatinib plasma concentrations above $1 \mu \mathrm{g} / \mathrm{mL}$ are associated with complete cytogenetic and major molecular responses to standard dose $(400 \mathrm{mg}$ once daily) in chronic myeloid leukemia. ${ }^{3}$ Variations in drug disposition, especially plasma clearance (CL), may result in excessive toxicity or suboptimal anticancer efficacy. The main toxicities of Imatinib are frequently dose-related. For instance, Neutropenia correlates with the area under the concentration time curve (AUC) of Imatinib. ${ }^{4}$ Owing to the exposure effect relationship, Imatinib is an ideal candidate for therapeutic drug monitoring (TDM) ${ }^{5}$ that would allow for optimization of dose to achieve improved molecular response in CML. ${ }^{6}$ Liquid chromatography mass spectrometry (LC-MS) and high performance liquid chromatography (HPLC) are widely used and clinically practiced methods for the detection of Imatinib levels. ${ }^{7}$

In view of long sample preparation time and nonavailability of instrumentation in standard hospital settings, there is a need to develop an alternative rapid yet accurate method for the determination of plasma Imatinib concentrations. Raman spectroscopic (RS) studies in biomedicine, pharmaceutics and homeland security applications (for detection of biomarkers, chemicals, explosives) have already been well documented..$^{8-10}$ Variants of RS such as drop coating deposition Raman (DCDR) and surface-enhanced Raman spectroscopy (SERS) are known to be sensitive and can facilitate detection up to single molecule level. With DCDR, a type of non-enhanced Raman spectroscopy, applications such as analyzing changes in the relative protein concentrations of aqueous tertiary protein mixtures and determination of albumin glycation have been reported. ${ }^{11-13}$ SERS is a well known and time-tested technique for ultrasensitive detection, analysis and imaging at single molecule level. ${ }^{14,15}$ This paper introduces the utility of Raman spectroscopy as a prospective tool for rapid monitoring of patients treated with Imatinib, at the therapeutic concentration of $1 \mu \mathrm{g} / \mathrm{mL}$ and above.

\section{Materials and Methods}

\subsection{Sample preparation}

Different concentrations of Imatinib ranging from $5 \mathrm{mg} / \mathrm{mL}$ to $1 \mu \mathrm{g} / \mathrm{mL}$ were spiked in ultrapure water (Milli-Q systems, Millipore Corporation and referred to as "milli-q" in the manuscript) and pooled plasma (obtained from blood banks). A series of stock solutions were prepared and serially diluted for their corresponding analysis. To ensure repeatability and reproducibility, each concentration was analyzed in triplicates and the experiment was repeated three times on different days.

\subsection{Raman spectroscopy}

\subsubsection{Instrumentation}

Spectra were recorded using fiberoptic Raman microprobe (Horiba-Jobin-Yvon, France), as described elsewhere. ${ }^{16}$ This Raman system consists of laser (785 nm, Process Instruments) as an excitation source and HE-785 spectrograph (Horiba-JobinYvon, France) coupled with CCD (Synapse, HoribaJobin-Yvon) as dispersion and detection elements, respectively. Optical filtering of unwanted noise, including Rayleigh signals, is accomplished through "Superhead", the other component of the system. Optical fibers were employed to carry the incident light from the excitation source to the sample and also to collect the Raman scattered light from the sample to the detection system. Raman microprobe was assembled by coupling a 40X (NA: 0.65) microscope objective (Nikon, Japan) to the superhead.

\subsubsection{Experimental approaches}

All spiked samples were subjected to conventional RS by placing approximately $10 \mu \mathrm{L}$ of sample on a $\mathrm{CaF}_{2}$ window. The spectra were recorded randomly from multiple points on each drop using the setup described above.

In case of DCDR, a volume of $10 \mu \mathrm{L}$ (sample spiked with drug) was deposited on $\mathrm{CaF}_{2}$ substrates 


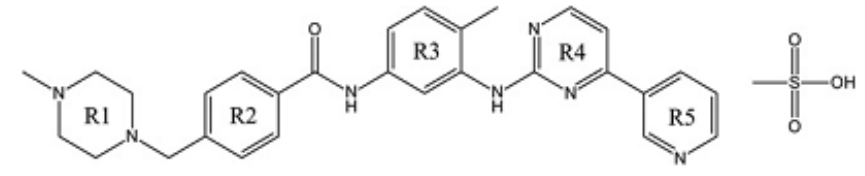

Table 1. Peak assignments for Imatinib.

\begin{tabular}{ll}
\hline $\begin{array}{l}\text { Imatinib saturated } \\
\text { solution }\left(\mathrm{cm}^{-1}\right)\end{array}$ & \multicolumn{1}{c}{ Assignment } \\
\hline 782 & $\mathrm{R} 3$ (methylbenzene ring) \\
996 & $\mathrm{R} 4$ (Aminopyrimidine ring) \\
& $\mathrm{S}=\mathrm{O}$ (mesylate salt) \\
1048 & $\mathrm{R} 1$ (N-methyl piperazine ring) \\
1324 & $\mathrm{R} 1$ (N-methyl piperazine ring) \\
1424 & $\mathrm{R} 5$ (Pyridine ring) \\
1615 & $\mathrm{R} 2$ \\
\hline
\end{tabular}

and allowed to dry for approximately $40 \mathrm{~min}$ in a Fume hood. The dried drop was subjected to RS. Spectra were acquired from one end of the drop (periphery) to the other (vertical direction). This was repeated by spanning the drop across the horizontal direction to investigate the presence of Imatinib in the dried drop.

SERS studies were carried out by depositing concave gold nanoparticles on glass substrates coated with aluminum foil substrates. Concave nanocubes were synthesized with slight modifications in the method reported by Zhang et al. ${ }^{17}$ In a typical synthesis, seeds were prepared in the following way: $260 \mu \mathrm{L}$ of $\mathrm{HAuCl}_{4}(10 \mathrm{mM})$ were added to a $10 \mathrm{~mL}$ of cetyltrimethylammonium chloride (CTAC) solution $(0.1 \mathrm{M})$, to initiate the seeds growth, $700 \mu \mathrm{L}$ of icecold freshly prepared $\mathrm{NaHB}_{4}$ solution $(10 \mathrm{mM})$ was

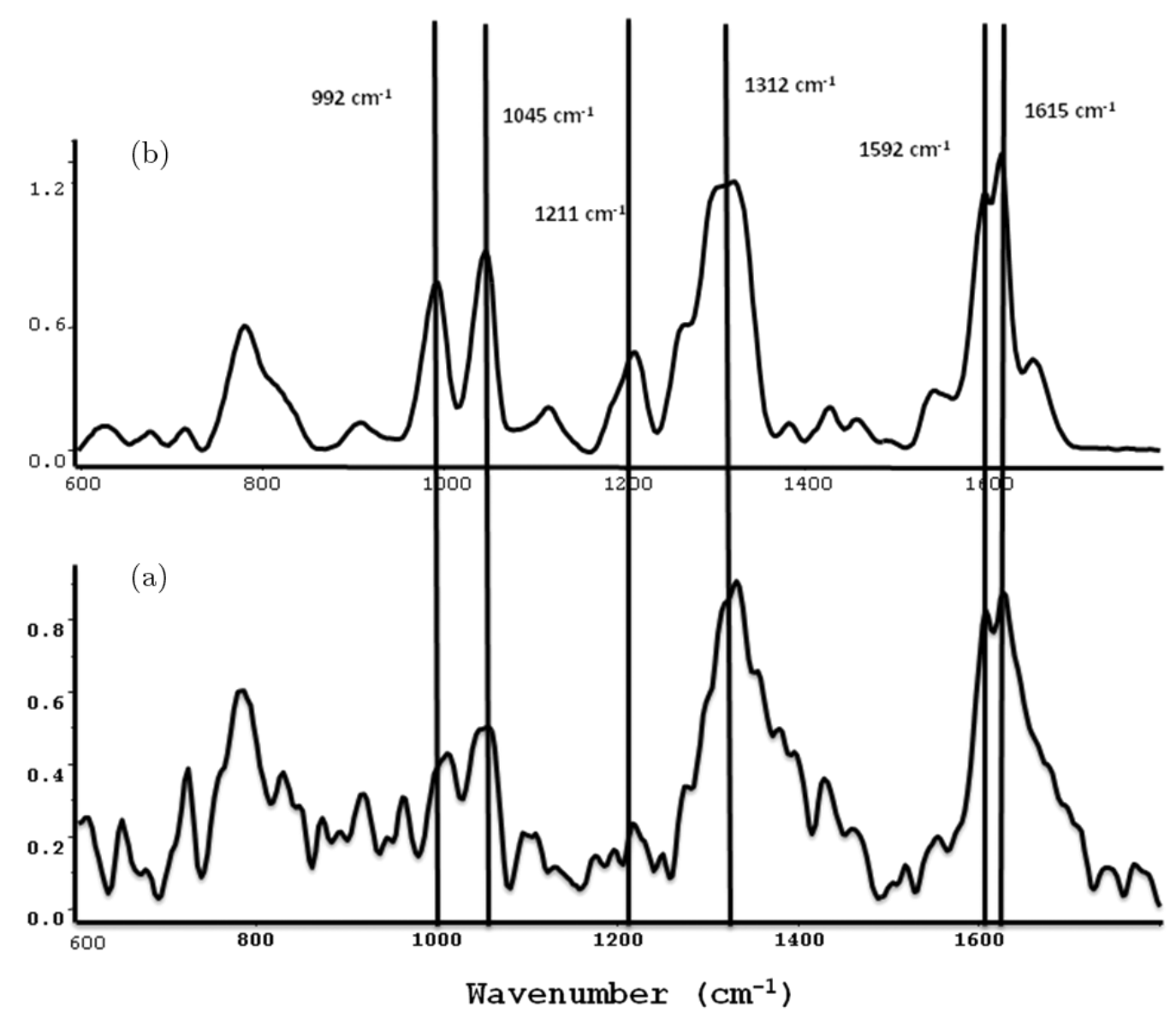

Fig. 1. Representative spectra for conventional Raman approach in drug spiked milli-q. Spectra were acquired from Imatinib spiked milli-q and representative spectra for 5 and $1 \mathrm{mg} / \mathrm{mL}$ are shown in the figure, (a) Lowest concentration: $1 \mathrm{mg} / \mathrm{mL}$, (b) Highest concentration: $5 \mathrm{mg} / \mathrm{mL}$. 


\section{S. Rath et al.}

added under continuous magnetic stirring and left standing for $2 \mathrm{~min}$ and finally left undisturbed for $2 \mathrm{~h}$. For concave nanocubes, growth solution was prepared by consecutively adding: $10 \mathrm{~mL}$ of CTAC $(0.1 \mathrm{M}), 500 \mu \mathrm{L}$ of $\mathrm{HAuCl}_{4}(10 \mathrm{mM}), 50 \mu \mathrm{L}$ of $\mathrm{AgNO}_{3}$ $(10 \mathrm{mM}), 200 \mu \mathrm{L}$ of $\mathrm{HCl}(1 \mathrm{M}), 125 \mu \mathrm{L}$ of ascorbic acid $(0.1 \mathrm{M}) .50 \mu \mathrm{L}$ of seeds solution diluted 1:100 were added to the growth solution to initiate the growth of the nanoparticles. The nanoparticles were harvested from the surfactants and other media components by centrifugation at $3500 \mathrm{rpm}$ for $30 \mathrm{~min}$. This washing step was repeated 3 times to obtain purified nanoparticles with minimal media components. ${ }^{18}$ SERS substrates were prepared by dropping
$20 \mu \mathrm{L}$ of purified nanoparticles on the surface of cleaned aluminum foil. After the nanoparticles dried, spiked water and plasma solutions were dropped onto the SERS substrate and the corresponding Raman spectra were acquired at random points of the sample.

Spectral acquisition parameters of laser power $30 \mathrm{~mW}$, acquisition time $-15 \mathrm{~s}$, average -4 were kept constant for all the measurements (CRS, DCDR and SERS). The laser spot size at the sample was $\sim 5-10 \mu \mathrm{m}$. About 10 spectra were recorded from different areas of the drop, in case of CRS and SERS. For DCDR, $\sim 15$ spectra were acquired from one end of the drop to the other, both horizontally and vertically as previously stated. The

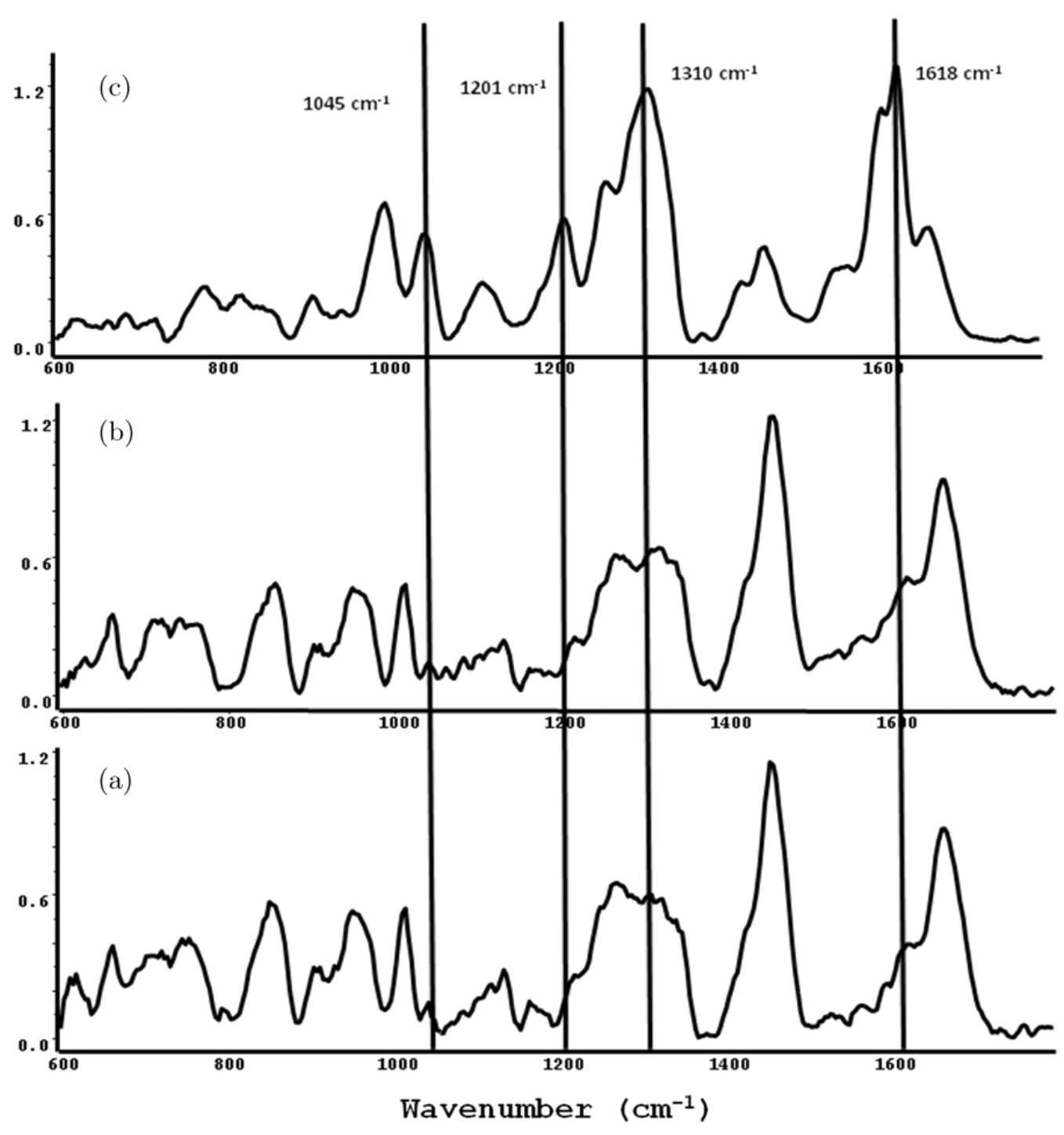

Fig. 2. Representative spectra for DCDR approach in drug spiked and blank plasma. DCDR approach was explored to achieve lower detection limit for Imatinib. Spectra were acquired from dried drop of Imatinib spiked plasma for concentrations 2, 1, $0.1 \mathrm{mg} /$ $\mathrm{mL}$ and blank plasma. Imatinib-specific signals could be observed till $0.1 \mathrm{mg} / \mathrm{mL}$; (a) blank plasma, (b) Lowest concentration: $0.1 \mathrm{mg} / \mathrm{mL}$, (c) Intermediate concentration: $1 \mathrm{mg} / \mathrm{mL}$, (d) Highest concentration: $2 \mathrm{mg} / \mathrm{mL}$. 
representative spectrum from each class has been shown in the manuscript.

\subsubsection{Spectra pre-processing}

Raman spectra were corrected for charged coupled device (CCD) response with a National Institute of Science and Technology (NIST) certified Standard Reference Material 2241 (SRM 2241) followed by the subtraction of background signals from optical elements and substrate. Spectra were interpolated in $600-1800 \mathrm{~cm}^{-1}$ region. Details of the spectral preprocessing are mentioned elsewhere ${ }^{16}$ Average spectra were computed from these background-subtracted and interpolated spectra. The typical spectra were baseline-corrected by fitting a fifth-order polynomial function using LabSpec 4.18 (Horiba Jobin Yvon, France). These baseline-corrected, smoothed (Savitzky-Golay, 3) and vector-normalized spectra were analyzed for detecting Raman signals attributable to Imatinib and computing difference spectra.

\section{Results and Discussion}

While RS has been used for various other applications discussed earlier, its use for detection of drugs like Imatinib in biological matrices has not been explored. Existing methods such as HPLC and

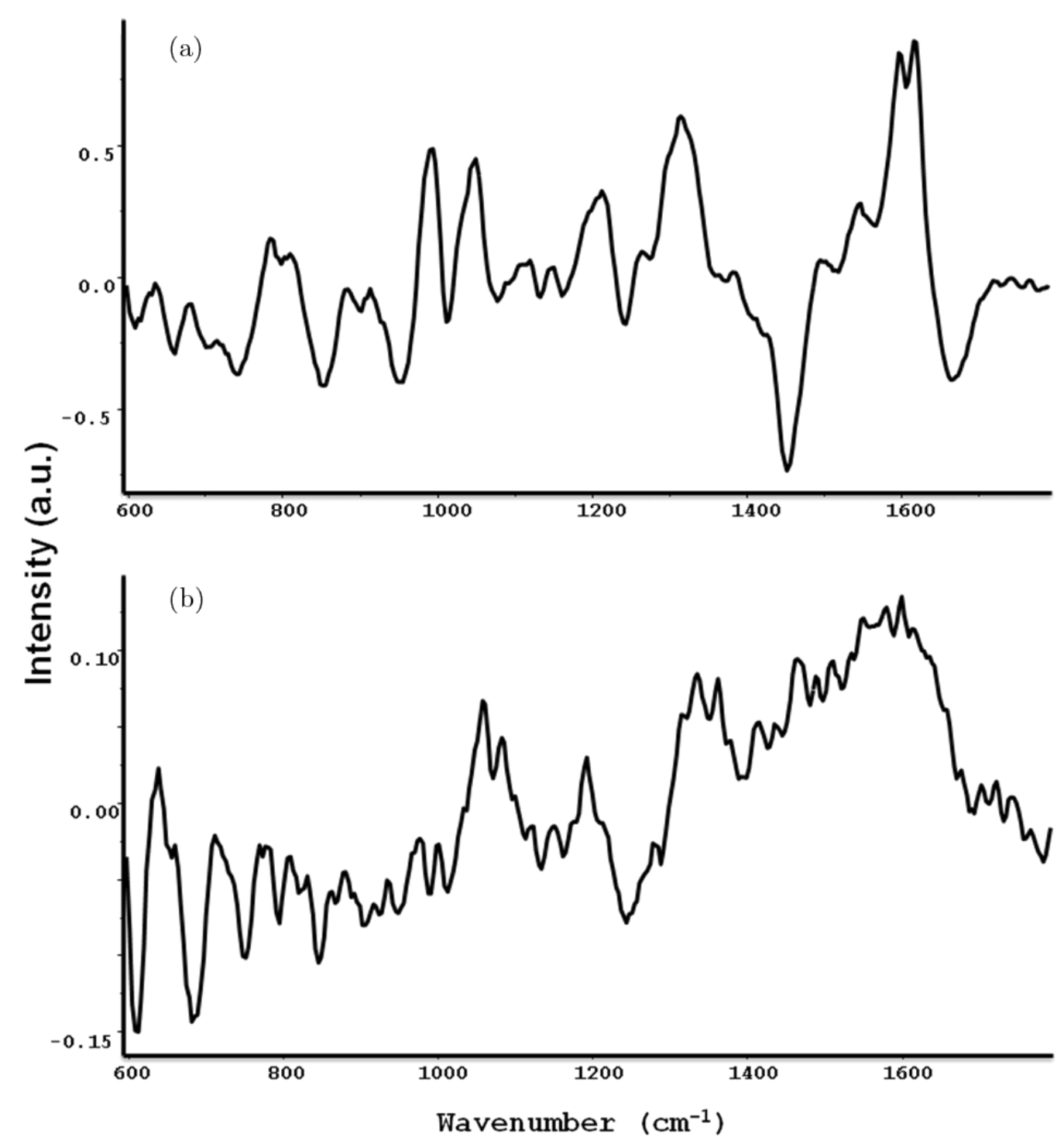

Fig. 3. Difference spectra for DCDR approach (a) Highest concentration (2 mg) — blank plasma, (b) Lowest concentration $(0.1 \mathrm{mg})$ - blank plasma. 


\section{S. Rath et al.}

LC-MS being used for the purpose are resourceconsuming and labor intensive. This prompted us to explore an alternative method for therapeutic monitoring of Imatinib. The RS method described here for the detection of Imatinib in plasma is the first to be reported so far.

The potential of Raman spectroscopy as therapeutic tool for detection of Imatinib was explored using three approaches: conventional Raman spectroscopy (CRS), DCDR and SERS. The chemical name for imatinib is 4-[(4-methyl-1-piperazinyl) methyl]-N-[4-methyl-3-[[4-(3-pyridinyl)2-pyrimidinyl]amino]-phenyl] benzamide methanesulfonate. For a pure/saturated Imatinib solution, spectra were acquired using the same experimental setup and bands were observed at positions 782 , 996, 1048, 1310, 1424, 1600 and $1623 \mathrm{~cm}^{-1}$. These bands can be attributed to the following structural components in Imatinib: $996 \mathrm{~cm}^{-1}$ band can be attributed to R4 (aminopyrimidine ring) and $v(\mathrm{~S}=\mathrm{O})$ (mesylate salt), $1048 \mathrm{~cm}^{-1}$ is assigned to $\mathrm{R} 1$ (N-methyl piperazine ring) and R5 (pyridine ring), $1310 \mathrm{~cm}^{-1}$ is attributed to $\mathrm{R} 1$ and $\mathrm{R} 2$ (benzamide ring). $1424 \mathrm{~cm}^{-1}$ can be assigned to $\mathrm{R} 4$ and R5 while R2 vibrations are associated with $1615 \mathrm{~cm}^{-1}$. Spectral assignments were made based on the available literature, and are also tabulated in Table $1 .{ }^{19,20}$ The same standard bands were used to identify Imatinib in the spiked samples.

\subsection{Conventional Raman spectroscopy}

The feasibility of detecting Imatinib was first evaluated using CRS in drug-spiked milli-q. The baseline corrected spectra acquired using CRS are shown in

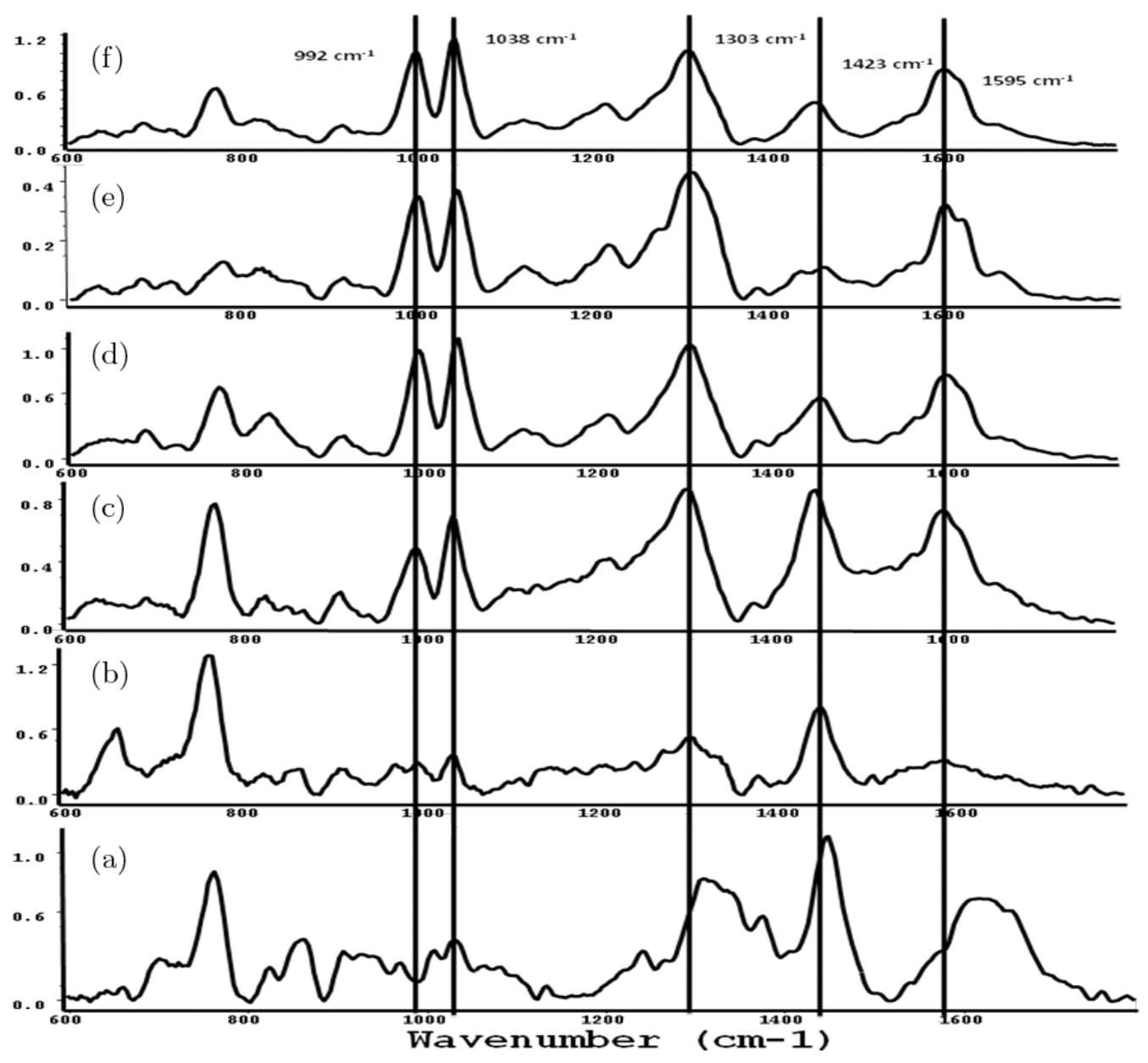

Fig. 4. Representative spectra for SERS approach in drug-spiked milli-q. SERS approach to achieve therapeutically relevant concentrations was first investigated in milli-q. Concentrations ranging from $1-0.001 \mathrm{mg} / \mathrm{mL}$ were spiked in milli-q and deposited on suitable nanoparticle substrates. Imatinib-specific signals could also be detected in the lowest concentration. (a) Blank nanoparticles, (b) Lowest concentration: $0.001 \mathrm{mg} / \mathrm{mL}(1 \mu \mathrm{g} / \mathrm{mL})$, (c) Concentration: $0.01 \mathrm{mg} / \mathrm{mL}$, (d) Concentration: $0.1 \mathrm{mg} / \mathrm{mL},(\mathrm{e})$ Concentration: $0.5 \mathrm{mg} / \mathrm{mL}$, (f) Highest concentration: $1 \mathrm{mg} / \mathrm{mL}$. 
Figs. 1(a) and 1(b). Major Raman bands indicating the presence of Imatinib in the highest concentration $(5 \mathrm{mg} / \mathrm{mL})$, were observed at $782,992,1045,1211$, 1312,1598 and $1615 \mathrm{~cm}^{-1}$ [Fig. 1(b)]. ${ }^{19,20}$ The lowest limit of detection of Imatinib using CRS was found to be $1 \mathrm{mg} / \mathrm{mL}$, where minor bands attributable to Imatinib were observed at 992,1045 and $1211 \mathrm{~cm}^{-1}$ [Fig. 1(a)]. The presence of Imatinib in $1 \mathrm{mg} / \mathrm{mL}$ was confirmed using difference spectra computed by subtracting blank milli-q from $1 \mathrm{mg} / \mathrm{mL}$ concentration (data not shown). Positive bands at 990, 1044, 1321,1598 and $1618 \mathrm{~cm}^{-1}$ verify the detection of Imatinib for this concentration. With a detection limit way above the desired therapeutic threshold of $1 \mu \mathrm{g} / \mathrm{mL}$, this approach proved to be inefficient for use from a clinical perspective.

\section{2. $D C D R$}

In order to improve sensitivity and evaluate the detection of Imatinib in human plasma, the technique of DCDR was employed. For these experiments, concentrations starting from $2 \mathrm{mg} / \mathrm{mL}$ up till $0.1 \mathrm{mg} / \mathrm{mL}$ of Imatinib spiked in plasma were employed. The baseline corrected spectra are shown in Figs. 2(a)-2(c). As seen in Fig. 2(a), major Raman bands for blank plasma were observed at 1660, 1450, 1265,1128 and $1008 \mathrm{~cm}^{-1}$ attributed to Amide I (protein), $\mathrm{CH}_{2}$ stretch (lipid and protein), Amide III (protein), C-N stretching (protein) and Phe, respectively along with bands at 946, 1114, 1306, 1320 and $1618 \mathrm{~cm}^{-1}$. For the highest concentration of drug-spiked plasma $(2 \mathrm{mg} / \mathrm{mL})$, major bands were observed at 996, 1045, 1114, 1214, 1262, 1313, 1457, 1598, 1618 and $1657 \mathrm{~cm}^{-1}$ [Fig. 2(c)]. The Imatinib reference spectra is suggestive that bands at 996, 1045, 12141313,1598 and $1618 \mathrm{~cm}^{-1}$ may be indicative of Imatinib. Imatinib-related bands were also observed in the successive lower concentrations, down to $0.1 \mathrm{mg} / \mathrm{mL}$, where bands at 1211,1313 and $1618 \mathrm{~cm}^{-1}$ [Fig. 2(b)] can be attributed to Imatinib. To confirm the presence of Imatinib, difference spectra were computed from the highest and lowest concentration by subtracting blank plasma spectra.

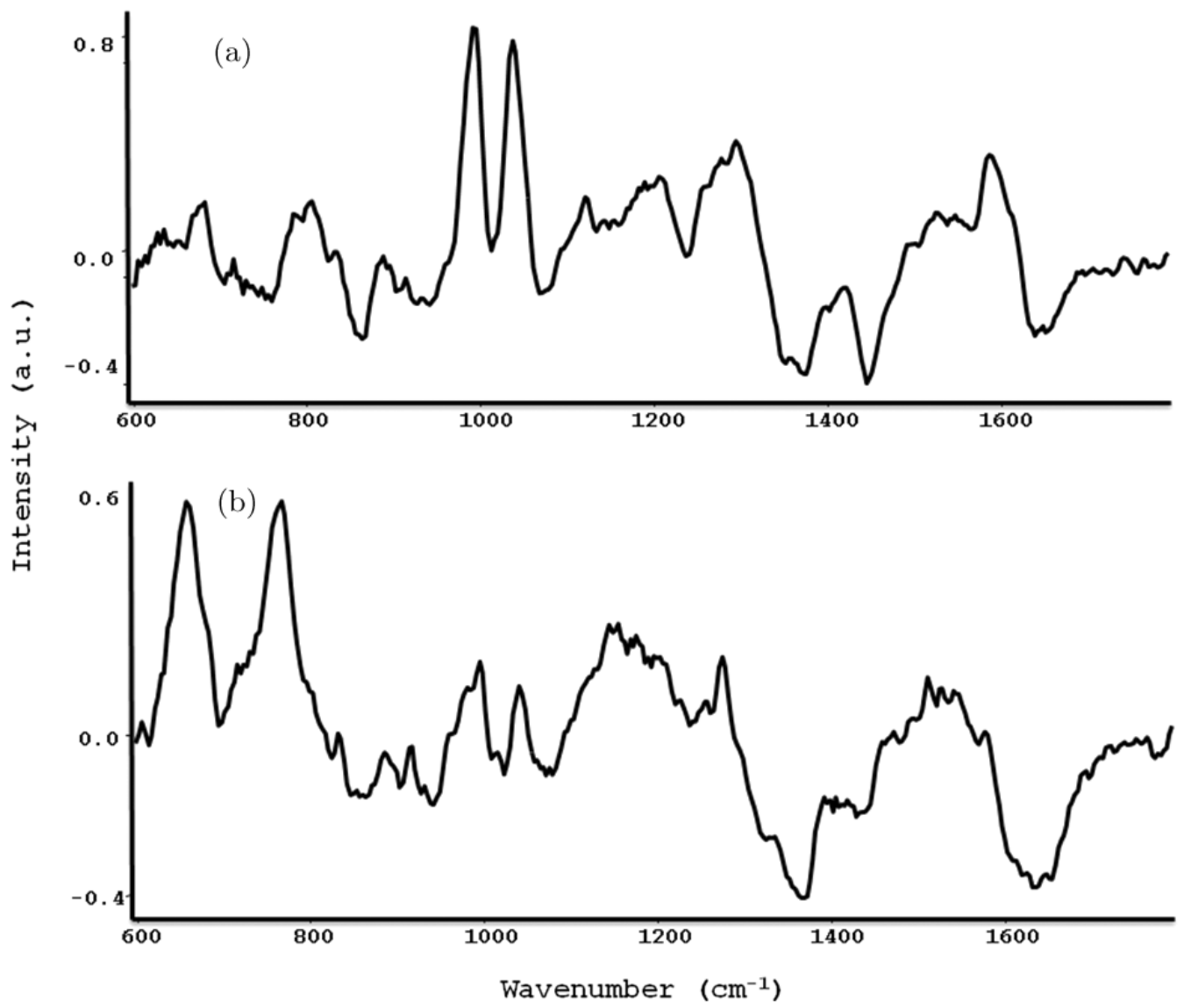

Fig. 5. Difference spectra for SERS approach. (a) Highest concentration (1 mg) — blank nanoparticle, (b) Lowest concentration $(1 \mu \mathrm{g})$ - blank nanoparticles. 


\section{S. Rath et al.}

As seen in the Fig. 3(a), positive bands at 998, 1049, $1211,1311,1595$ and $1615 \mathrm{~cm}^{-1}$ indicate the presence of Imatinib in the difference spectrum $(2 \mathrm{mg}-$ blank) for a concentration of $2 \mathrm{mg} / \mathrm{mL}$. Negative bands at 1240, 1270, 1450 and $1660 \mathrm{~cm}^{-1}$ correspond to contributions from plasma, and are not drug features. In the lowest concentration difference spectrum (0.1 mg - blank), two minor bands at 1595 and $1615 \mathrm{~cm}^{-1}$ reflect the presence of Imatinib. Thus, DCDR enabled the detection of concentration as low as $0.1 \mathrm{mg} / \mathrm{mL}$, but it failed to achieve detection of therapeutically relevant concentration i.e., $1 \mu \mathrm{g} / \mathrm{mL}$.

\subsection{SERS}

SERS was consequently explored for detecting Imatinib at clinically relevant concentrations, owing to its sensitivity up to the single molecule level. Feasibility SERS experiments were initially carried out in milli-q for drug concentrations of 1 , $0.5,0.1,0.01$ and $0.001 \mathrm{mg} / \mathrm{mL}$, baseline corrected spectra are shown in Fig. 4. In case of drug-spiked water, highly intense bands were observed in higher concentrations $(1,0.5$ and $0.1 \mathrm{mg} / \mathrm{mL})$ at 992,1034 , 1303 and $1595 \mathrm{~cm}^{-1}$ due to enhancements because of drug-metal interactions [Figs. 4(d)-4(f)]. Other bands observed at 763 and $1207 \mathrm{~cm}^{-1}$ could also be attributed to Imatinib. In the lowest concentration of $0.001 \mathrm{mg} / \mathrm{mL}(1 \mu \mathrm{g} / \mathrm{mL})$, imatinib-related bands were observed at 995, 1034 and $1303 \mathrm{~cm}^{-1}$ [Fig. 4(b)]. Difference spectra were computed to confirm this limit of detection. Blank nanoparticle spectrum was subtracted from the highest $(1 \mathrm{mg} / \mathrm{mL})$ and lowest concentrations $(1 \mu \mathrm{g} / \mathrm{mL})$, as shown in Fig. 5 . Positive bands at 990, 1034, 1294 and $1585 \mathrm{~cm}^{-1}$ in

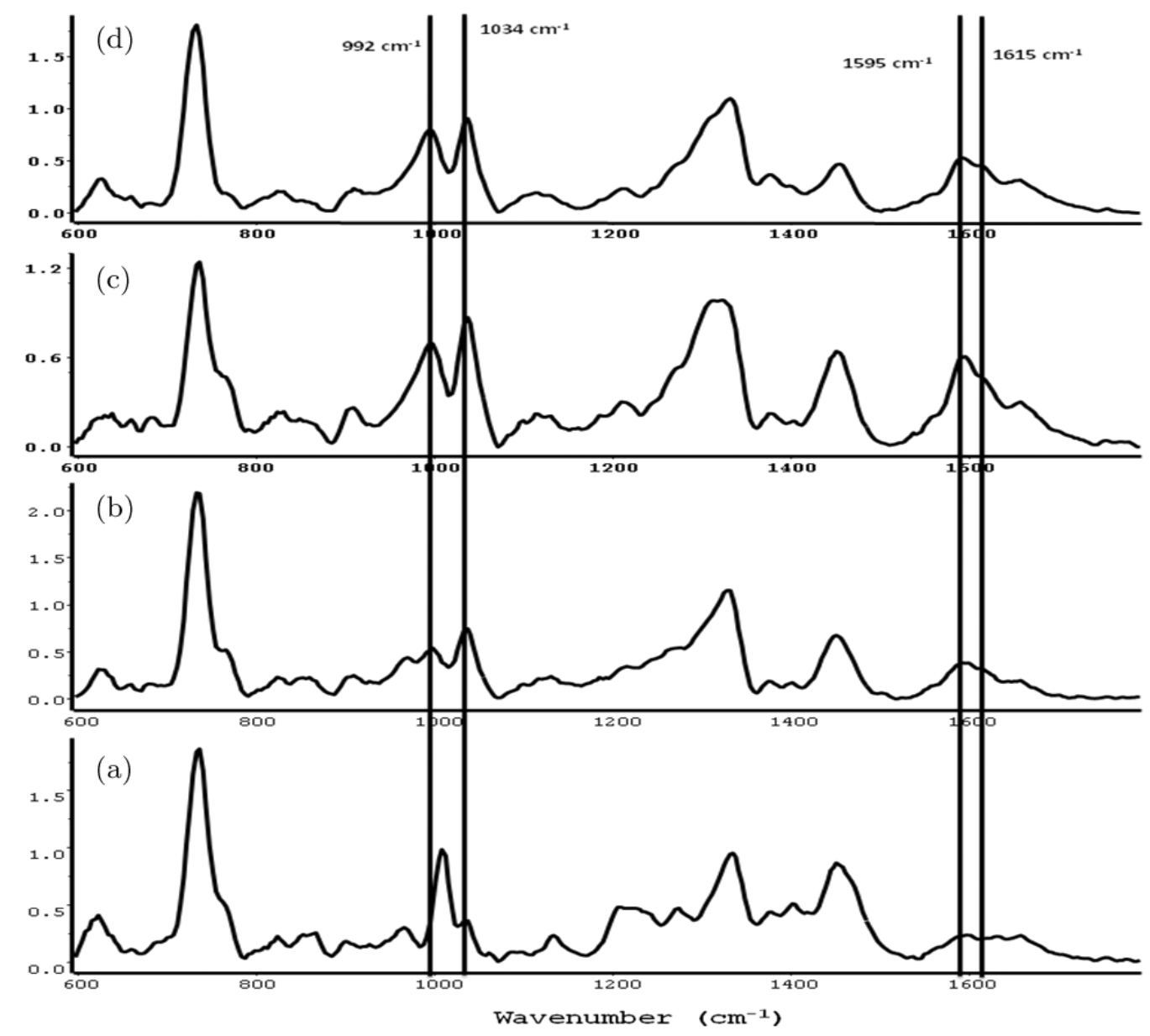

Fig. 6. Representative spectra for SERS approach in drug-spiked plasma. SERS approach to achieve therapeutically relevant concentrations was then investigated in drug-spiked plasma. Concentrations ranging from 0.1-0.001 mg/mL were spiked in plasma and deposited on suitable nanoparticle substrates. Imatinib-specific signals could also be detected in the lowest concentration. (a) Blank plasma, (b) Lowest concentration: $0.001 \mathrm{mg} / \mathrm{mL}(1 \mu \mathrm{g} / \mathrm{mL})$, (c) Concentration: $0.005 \mathrm{mg} / \mathrm{mL}$, (d) Highest concentration: $0.1 \mathrm{mg} / \mathrm{mL}$. 
Fig. 5(a) can be attributed to Imatinib. In the lowest concentration difference spectrum, major positive bands were observed at 653, 763, 992, 1038 and $1152 \mathrm{~cm}^{-1}$. Of these, bands at 992 and $1034 \mathrm{~cm}^{-1}$ may be indicative of Imatinib detection at this concentration $(1 \mu \mathrm{g} / \mathrm{mL})$. Further, the feasibility of detecting Imatinib in drug-spiked plasma was evaluated (Fig. 6). The concentrations 0.1, 0.005 and $0.001 \mathrm{mg} / \mathrm{mL}$ were spiked in plasma. The highest concentration showed bands at 992, 1034, 1592 and $1615 \mathrm{~cm}^{-1}$ [Fig. 6(d)], while minor bands could also be observed at similar band positions in the $1 \mu \mathrm{g} / \mathrm{mL}$ concentration [Fig. 6(b)] with respect to blank plasma [Fig. 6(a)]. A difference spectrum was calculated by subtracting blank plasma from the highest $(0.1 \mathrm{mg} / \mathrm{mL})$ and lowest concentration $(1 \mu \mathrm{g} / \mathrm{mL})$. Major positive bands for the highest concentration difference spectrum was seen at 719, 985, 1034, 1107,
1303, 1592 and $1611 \mathrm{~cm}^{-1}$, of which $985,1034,1303$, 1592 and $1618 \mathrm{~cm}^{-1}$ can be attributed to Imatinib [Fig. 7(a)]. In the lowest concentration difference spectra, positive bands were observed at 727,985 , 1034, 1114, 1176, 1259, 1296 and $1592 \mathrm{~cm}^{-1}$. Bands at $985,1034,1296$ and $1592 \mathrm{~cm}^{-1}$ can be attributed to Imatinib [Fig. 7(b)]. Thus, the therapeutic detection limits of $1 \mu \mathrm{g} / \mathrm{mL}$ was achieved using both drugspiked milli-q and plasma. The reproducibility of the approach was confirmed by multiple repetitions of the experiment. Thus, SERS with suitable nanoparticles substrates can lead to peak enhancements that enabled detection at the required therapeutic concentration of $1 \mu \mathrm{g} / \mathrm{mL}$.

The advantage of using RS-based approach for drug monitoring of Imatinib is the objectivity, rapidity and the minimal sample preparation requirements. As SERS-nanoparticles-based approach can achieve

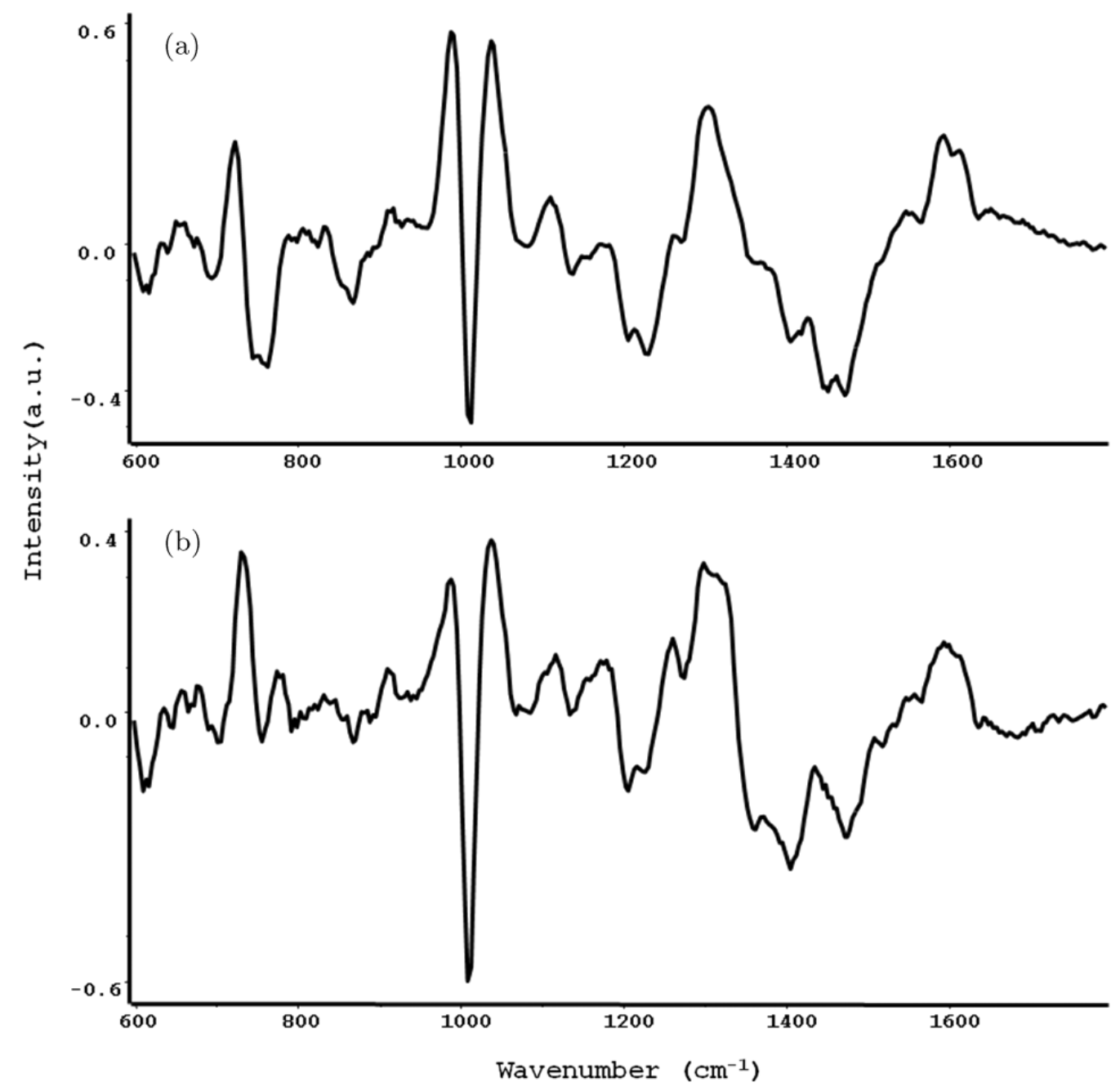

Fig. 7. Difference spectra for SERS approach. (a) Highest concentration (0.1 mg) — blank plasma, (b) Lowest concentration $(1 \mu \mathrm{g})$ - blank plasma. 
the therapeutic detection limits, this approach can be adopted for all future clinical applications. Coating of aluminum substrates with the synthesized nanoparticles is a simple and standardized procedure. Thus, manufacturing ready-to-use substrates on a large scale is not labor intensive. For clinical applications, blood samples from visiting patients can be collected, placed on the alreadyprepared substrate, and spectral acquisition can be done. The spectra can then be tested against existing standard models of the therapeutically relevant trough and peak concentrations. Drug levels in patients can then be inferred from the result of the test prediction. Thus, an immediate decision on optimal dose can be made. Although, availability of onsite instrumentation at all clinical centers can be a limiting factor, samples can be collected and transported to a centralized facility for Raman analysis, and results can be sought within a few hours of sample receipt.

\section{Conclusion}

RS, DCDR and SERS approaches were explored for the detection of Imatinib at therapeutic concentration of $1 \mu \mathrm{g} / \mathrm{mL}$ and above. Of these, SERS-nanoparticle-based approach can be a more practical and efficient tool for TDM of Imatinib in clinics.

Although HPLC, LC-MS are sensitive as well as precise methods for determination of Imatinib concentration, this study has been designed specifically to detect imatinib at the concentration of $1 \mu \mathrm{g} / \mathrm{mL}$ and above. We would like limit the sensitivity to $1 \mu \mathrm{g} / \mathrm{mL}$ and above as that is our therapeutic threshold and detection at lower levels may not have clinical utility. Thus, CRS, DCDR and SERS approaches were explored for the detection of Imatinib at therapeutic concentration of $1 \mu \mathrm{g} / \mathrm{mL}$ and above. The current study is a proof of concept which introduces a semiquantitative assay for detection of Imatinib in human plasma. Prospective rigorous validation using clinical samples is required to establish Raman-spectroscopy as a rapid and objective tool for routine clinical usage. This concept can be extended for other drugs which are candidates for TDM.

\section{Acknowledgments}

This work was carried out under joint Indo-Mexican project titled "Synthesis, optical and photo-thermal characterization of metallic nanoparticles for biomedical applications", funded by Department of Science and Technology, Government of India and CONACyt, Mexico.

\section{Conflict of Interest}

None.

\section{References}

1. K. Eechoute, A. Sparreboom, H. Burger, R. M. Franke, G. Schiavon, J. Verweij, W. J. Loos, E. A. Wiemer, R. H. Mathijssen, "Drug transporters and imatinib treatment: Implications for clinical practice," Clin. Cancer Res. 17(3), 406-415 (2011).

2. A. Petain, D. Kattygnarath, J. Azard, E. Chatelut, C. Delbaldo, B. Geoerger, M. Barrois, S. SeronieVivien, A. LeCesne, G. Vassal, "Population pharmacokinetics and pharmacogenetics of imatinib in children and adults," Clin. Cancer Res. 14(21), 7102-7109 (2008).

3. S. Picard, K. Titier, G. Etienne, E. Teilhet, D. Ducint, M. A. Bernard, R. Lassalle, G. Marit, J. Reiffers, B. Begaud, N. Moore, M. Molimard, F. X. Mahon, "Trough imatinib plasma levels are associated with both cytogenetic and molecular responses to standard-dose imatinib in chronic myeloid leukemia," Blood 109(8), 3496-3499 (2007).

4. C. Delbaldo, E. Chatelut, M. Ré, A. Deroussent, S. Séronie-Vivien, A. Jambu, P. Berthaud, A. Le Cesne, J.-Y. Blay, G. Vassal, "PharmacokineticPharmacodynamic relationships of imatinib and its main metabolite in patients with advanced gastrointestinal stromal tumors," Clin. Cancer Res. 12(20), 6073-6078 (2006).

5. S. Bouchet, B. Royer, C. Le Guellec, K. Titier, "Therapeutic drug monitoring of tyrosine-kinase inhibitors in the treatment of chronic myelogenous leukaemia: Interests and limits," Therapie 65(3), 213-218 (2010).

6. T. P. Hughes, S. Branford, "Monitoring disease response to tyrosine kinase inhibitor therapy in CML," Hematology 1, 477-487 (2009).

7. M. Miura, N. Takahashi, K. Sawada, "Quantitative determination of imatinib in human plasma with high performance liquid chromatography and ultraviolet detection," J. Chromatogr. Sci. 49(5), 412-415 (2011).

8. R. S. Golightly, W. E. Doering, M. J. Natan, "Surface-enhanced Raman spectroscopy and homeland security: A perfect match?," ACS Nano $\mathbf{3}(10)$, 2859-2869 (2009). 
9. Q. Tu, C. Chang, "Diagnostic applications of Raman spectroscopy," Nanomedicine 8(5), 545-558 (2012).

10. S. Wartewig, R. H. Neubert, "Pharmaceutical applications of mid-IR and Raman spectroscopy," Adv. Drug Deliv. Rev. 57(8), 1144-1170 (2005).

11. N. C. Dingari, G. L. Horowitz, J. W. Kang, R. R. Dasari, I. Barman, "Raman spectroscopy provides a powerful diagnostic tool for accurate determination of albumin glycation," PLoS One 7(2), e32406 (2012).

12. J. Filik, N. Stone, "Drop coating deposition Raman spectroscopy of protein mixtures," Analyst 132, 544-550 (2007).

13. D. Zhang, Y. Xie, M. F. Mrozek, C. Ortiz, V. J. Davisson, D. Ben-Amotz, "Raman detection of proteomic analytes," Anal. Chem. 75(21), 57035709 (2003).

14. K. Kneipp, Y. Wang, H. Kneipp, L. T. Perelman, I. Itzkan, R. R. Dasari, M. S. Feld, "Single molecule detection using surface-enhanced Raman scattering (SERS)," Phys. Rev. Lett. 78, 1667 (1997).

15. W. Xie, S. Schlucker, "Medical applications of surface-enhanced Raman scattering," Phys. Chem. Chem. Phys. 15(15), 5329-5344 (2013).
16. A. Sahu, K. Dalal, S. Naglot, P. Aggarwal, C. M. Krishna, "Serum based diagnosis of asthma using Raman spectroscopy: An early phase pilot study," PLoS One 8(11), e78921 (2013).

17. J. Zhang, M. R. Langille, M. L. Personick, K. Zhang, S. Li, C. A. Mirkin, "Concave cubic gold nanocrystals with high-index facets," J. Am. Chem. Soc. 132, 14012-14014 (2010).

18. Y. P. de León, J. Pichardo-Molina, N. A. Ochoa, "Growth kinetics of concave nanocubes studied by optical coherence tomography," Plasmonics $\mathbf{9}$, 907-915 (2014).

19. A. Srivastava, B. Joshi, P. Tandon, A. Ayala, A. Bansal, D. Grillo, "Study of polymorphism in imatinib mesylate: A quantum chemical approach using electronic and vibrational spectra," Spectrochim. Acta A 103, 325-332 (2013).

20. F. S. Parker, Applications of Infrared, Raman and Resonance Raman spectroscopy in Biochemistry, Plenum Press, New York and London (1983). 